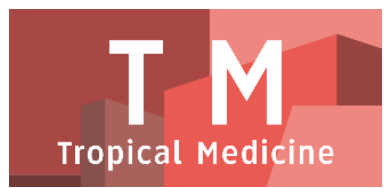

PAPER - OPEN ACCESS

\title{
Perawatan Gigi Natal dengan General Anastesi pada Bayi Usia 3 Bulan : Laporan Kasus
}

\author{
Author : Siti Salmiah \\ DOI $\quad: 10.32734 / \mathrm{tm} . v 1 i 1.68$ \\ Paper Page : $197-201$
}

Volume 1 Issue 1 - 2018 TALENTA Conference Series: Tropical Medicine (TM)

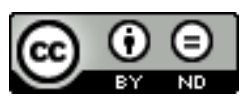

This work is licensed under a Creative Commons Attribution-NoDerivatives 4.0 International License.

Published under licence by TALENTA Publisher, Universitas Sumatera Utara
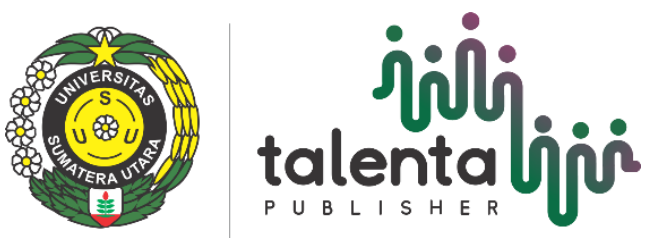


\title{
Perawatan Gigi Natal dengan General Anastesi pada Bayi Usia 3 Bulan : Laporan Kasus
}

\author{
Siti Salmiah ${ }^{\mathrm{a}}$ \\ ${ }^{a}$ Fakultas Kedokteran Gigi, Universitas Sumatera Utara, Medan 20155, Indonesia \\ salmiadentist@yahoo.co.id
}

\begin{abstract}
Abstrak
Gigi natal dan neonatal merupakan kasus gigi yang tumbuh sejak bayi lahir atau selama 30 hari setelah bayi lahir. Kasus ini merupakan kelainan erupsi pada gigi desidui, dimana gigi erupsi sebelum atau lebih cepat dari waktunya. Insidensi gigi natal berkisar 1: 2000 sampai 1: 3000 angka kelahiran. Gigi natal dan neonatal biasanya tumbuh pada rahang bawah bagian depan sehingga menyebabkan masalah dalam pemberian ASI, karena gigi tersebut menyebabkan luka pada gingiva, mukosa oral, lidah bayi dan puting susu ibu. Selain itu, karena gigi belum terbentuk sempurna dan hanya berpegang pada tepi gusi menyebabkan gigi goyang. Hal ini dikhawatirkan gigi dapat terlepas dan tertelan sehingga dapat menyebakan gangguan pernafasan. Pada kasus ini, bayi lahir dengan gigi sudah erupsi pada rahang bawah bagian depan. Orangtua tidak langsung membawa bayi kedokter gigi dan membiarkan saja kondisi tersebut sampai bayi berusia 3 bulan dan gigi sudah menyebabkan pembengkakan dan ulkus digingiva anterior rahang bawah dan atas, dilabial rahang atas dan permukaan ujung lidah. Kondisi ini menyebabkan bayi tidak mau minum susu sehingga berat badannya turun. Perawatan pada gigi natal ini dilakukan ekstraksi dengan general anastesi karena kondisi bayi tidak memungkinkan untuk dikerjakan diunit dental praktek dokter gigi. Kesimpulannya perawatan gigi natal harus segera dilakukan sebelum menimbulkan masalah lebih lanjut pada bayi.
\end{abstract}

Kata kunci : gigi natal; gigi neonatal; ekstraksi; bayi

\section{Pendahuluan}

Gigi Natal adalah gigi yang sudah tumbuh sejak bayi lahir. Sedangkan gigi neonatal adalah gigi yang tumbuh dalam 30 hari pertama sejak bayi lahir [1]. Kasus gigi natal dan neonatal adalah kelainan erupsi pada gigi desidui dimana gigi desidui erupsi sebelum waktu atau gigi desidui yang tumbuh lebih cepat dari waktunya [3]. Insidensi terjadinya gigi natal berkisar antara 1: 2,000 hingga 1: 3,500 dari kelahiran. Kejadiaannya sering pada perempuan dibandingkan laki-laki. Gigi natal sering dijumpai pada insisivus sentralis rahang bawah. Erupsi gigi natal sering erupsi secara berpasangan, dan jarang dijumpai melebihi dari dua gigi. Kurang dari 10\% gigi natal merupakan gigi supernumerary. Ronsen foto dapat dilakukan untuk membedakan gigi natal dan supernumerary teeth [4].

Kasus gigi natal sebenarnya jarang terjadi dan biasanya merupakan kelainan yang tidak berkaitan dengan penyakit lain, tapi kelainan ini juga bisa merupakan bagian dari sindroma tertentu, yaitu penyakit yang memiliki berbagai macam gejala misalnya, Ellis-van Creveld syndrome, Hallermann-Streiff syndrome, Pierre Robin syndrome, atau Soto's syndrome [1]. Etiologi gigi natal masih tidak diketahui pada saat ini. Infeksi, trauma, 
malnutrisi, posisi benih gigi yang superfisial, stimulasi hormon dan ibu hamil yang mengalami keadaan bertoksin juga dapat menjadi faktor penyebab terjadinya kasus gigi natal [4].

Gigi natal biasanya tumbuh pada rahang bawah depan yaitu di tempat gigi insisivus rahang bawah akan tumbuh. Biasanya gigi tersebut goyang karena akarnya belum terbentuk dengan sempurna dan hanya berpegang pada tepi gusi. Posisi gigi natal dapat menyebabkan masalah dalam pemberian ASI karena gigi ini dapat menyebabkan luka pada ibu saat menyusui dan juga luka pada lidah bayi. Selain itu juga terdapat resiko bagi gigi ini tertelan dan menyebabkan gangguan pernafasan [3]. Antara komplikasi lain adalah ulkus sublingual (Riga-Fede disease) dengan terganggunya asupan ASI[4]. Riga-fede adalah penyakit traumatik mukosa yang ditandai dengan ulserasi terus menerus dari mukosa oral. Paling sering melibatkan daerah permukaan ventral lidah atau frenulum lingual karena lidah berada diatas gigi. Lesi biasanya dimulai dengan daerah ulserasi dengan trauma berulang dan mungkin dapat berkembang menjadi besar, massa fibrous dengan gambaran ulseratif granuloma. Perawatannya perlu dilakukan ekstraksi pada kasus riga-fede yang tidak dapat disembuhkan, gigi yang hipermobiliti atau peningkatan kemungkinan tertelannya gigi.

\section{Laporan Kasus}

Seorang bayi perempuan (NAR) berusia 3 bulan 5 hari datang dibawa ibunya ke RS H. Adam Malik Medan dengan keluhan bayi selalu rewel, menangis dan muntah saat minum susu. Keadaan ini sudah berlangsung selama 1 bulan, sehingga berat badan bayi turun sebanyak 7 ons. Bayi merupakan pasien lama unit kardiologi anak dengan diagnosis Patent Ductus Arteriosus (PDA) kecil dan direncanakan operasi repair palatum atau palatoschisis.

Hasil pemeriksaan ekstra oral diperoleh bentuk muka, bibir, dan pipi normal tidak terdapat kelainan, serta berat badan bayi 3.600 gr. Pemeriksaan intra oral, terdapat gigi desidui yang sudah tumbuh pada regio anterior rahang bawah, adanya pembengkakan dan ulkus digingiva anterior rahang bawah dan atas, dilabial rahang atas dan permukaan ujung lidah. Ulkus mulai terlihat kurang lebih 1 bulan yang lalu. Gigi tersebut mobility derajat 1 , bentuknya tajam dan sudah ada ketika bayi lahir. Pemeriksaan radiologi tidak dapat dilakukan karena pasien masih bayi, sehingga tidak dapat diketahui apakah gigi tersebut gigi desiduinya atau gigi supernumerary. Adanya celah langit-langit menyebabkan bayi susah untuk menghisap puting susu ibu ataupun dot sehingga bayi diberikan susu menggunakan sendok.

\section{Penatalaksanaan Kasus}

Perawatan awal yang diberikan adalah penambalan bagian yang tajam pada gigi insisivus rahang bawahnya dengan menggunakan bahan restorasi GIC (gambar 1). Setelah 1 minggu penambalan, terlihat ulkus berkurang. Mobility gigi menjadi derajat 2 dan dikhawatirkan akan lepas dan tertelan bayi, sehingga gigi tersebut direncanakan untuk diekstraksi. Perawatan ekstraksi direncanakan dilakukan bersamaan dengan pencetakan untuk pembuatan feeding plate dengan menggunakan general anastesi. Pilihan penggunaan general anastesi karena bayi tidak kooperatif untuk dilakukan ekstraksi dan pencetakan di unit dental praktek dokter gigi. 


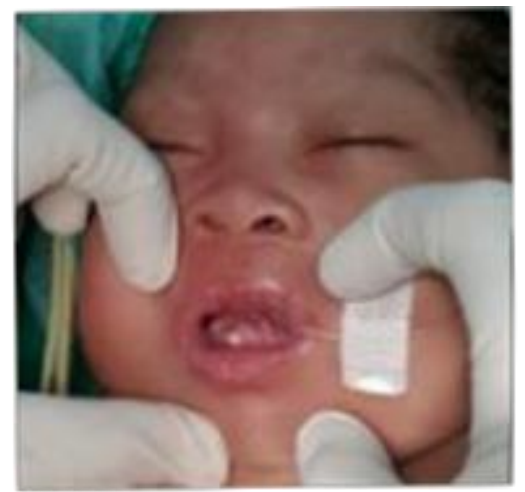

Gambar 1. Gigi natal (bayi perempuan, usia 3 bulan)

Sebelum dilakukan tindakan general anastesi, pasien diinapkan di RS HAM untuk pemeriksaan pre operasi. Pasien dikonsultasi ke drg spesialis bedah mulut, dokter spesialis anak dan dokter anastesi untuk rencana tindakan operasi bersama. Persiapan lain adalah pemeriksaan urine, darah dan thorax foto. Pasien diminta puasa (tidak minum susu) mulai tengah malam sebelum hari operasi untuk menghindari terjadinya aspirasi yang dapat menimbulkan hal yang tidak diinginkan. Pada pagi hari sebelum operasi dilakukan, pasien diperiksa oleh dokter spesialis anastesi, semua alat dan bahan untuk perawatan gigi disiapkan diruang operasi. Pasien dibawa ke ruang operasi, dianastesi (intubasi melalui hidung), diberi sumbat tenggorok (oropharynx pack) dan pasien siap dirawat giginya. Sebelum perawatan dimulai pada mukosa dan sekitar rongga mulut diulasi desinfektan (Betadine).

Perawatan yang dilakukan pertama kali adalah pencetakan rahang atas pasien utk pembuatan feeding plate oleh drg spesialis prostho. Selanjutnya dilakukan persiapan ekstraksi gigi natal. Anastesi lokal dengan menggunakan pehacain diberikan pada regio gigi natal yang akan diekstraksi (gambar 2). Gigi dikeluarkan dengan menggunakan bien (gambar 3), dan perdarahan pada gingiva dihentikan dengan menggunakan kassa steril (gambar 4). Pada saat dilakukan perawatan ditemukan adanya dua gigi yang bersebelahan dengan gigi insisivus rahang bawah tersebut dekat kegingiva sehingga gigi tersebut ikut keluar saat pencabutan dilakukan (gambar 5).

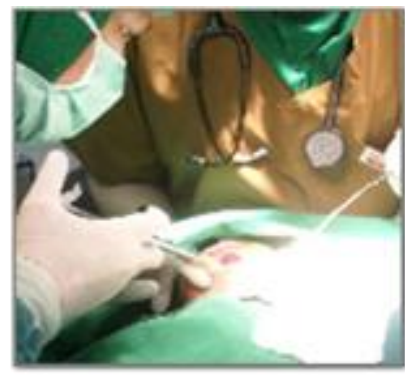

Gambar 2. Anastesi lokal dengan menggunakan pehacain

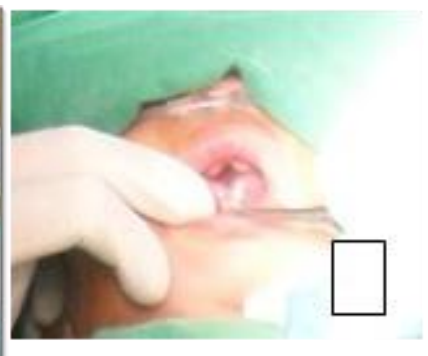

Gambar 3. Gigi dikeluarkan dengan menggunakan bein

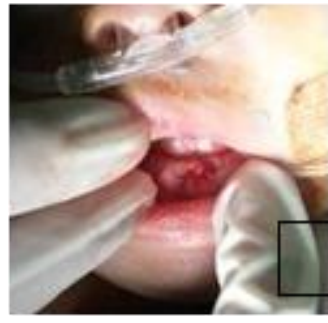

Gambar 4. Gingiva pasca pencabutan

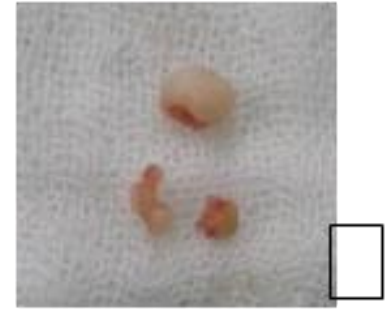

Gambar 5. Gigi natal yang telah diekstraksi

Setelah selesai perawatan pasien dibangunkan oleh dokter spesialis anastesi. Pemberian obat-obatan stetelah operasi meliputi antibiotika, analgesik, anti inflamasi, vitamin dan antimicrobial mouth rinse untuk mencegah terjadinya perdarahan. Pasien dipindahkan ke ruang pemulihan. Orang tua boleh ikut menjaga sambil diberi penjelasan apa yang sudah dikerjakan dan apa yang harus dilakukan. Evaluasi beberapa jam kemudian pasien dipindahkan kembali ke kamarnya. Instruksi kepada orangtua pasien untuk tetap membersihkan bagian dalam mulut 
dan lidah pasien pada malam hari dan pagi setelah minum susu serta menekankan tampon pada bekas luka pencabutan agar darah cepat berhenti. Dokter spesialis anak memberikan instruksi untuk obat-obatan dan cara pemberian susu.

Pemeriksaan hari berikutnya setelah operasi keadaan umum pasien sudah membaik dan oleh dokter spesialis anak diijinkan pulang. Pemeriksaan rongga mulut tidak ada perdarahan, $\mathrm{OH}$ pasien baik dan pasien diijinkan pulang sore harinya. Instruksi pada orang tua untuk menjaga kebersihan rongga mulut, pemberian susu dan obat diteruskan. Setelah 1 minggu perawatan gingiva tidak terlihat membengkak dan ulkusnya hilang dan bayi sudah mau minum susu dan berat badannya naik 3 ons (gambar 6).

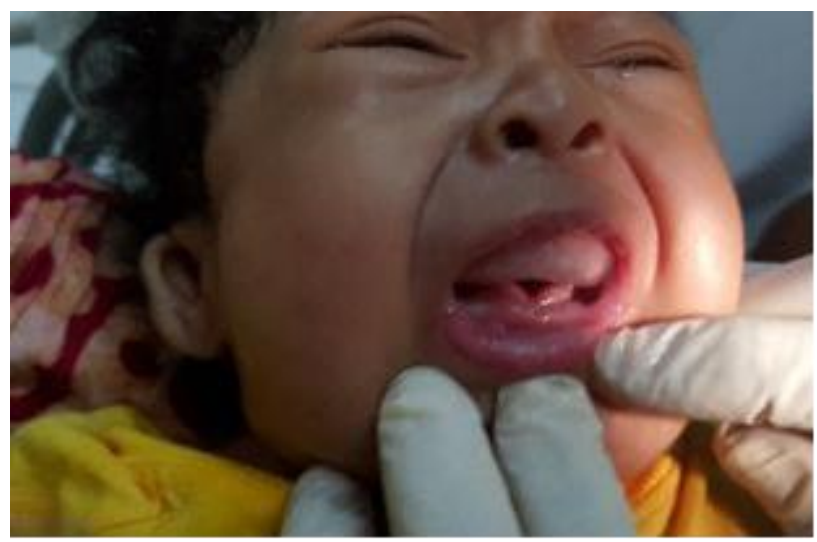

Gambar 6. Gambaran klinis setelah 1 minggu ekstraksi

\section{Pembahasan}

Meskipun kasus gigi natal jarang terjadi tetapi tidak menutup kemungkinan akan kita dapati pada praktek seharihari. Penting untuk mengambil keputusan yang tepat dalam hal penanganannya sehingga tidak memberikan efek merugikan baik pada bayi maupun sang ibu.

Lebih dari 90\% kasus gigi natal dilaporkan sebagai erupsi yang prematur, dan 1-10\% gigi yang erupsi ini sebagai supernumerary [6] dan ( Galassi MS dkk, 2004). Gigi natal frekwensinya lebih sering terjadi di regio insisivus depan rahang bawah yaitu sekitar 80-90\% [6]. Gigi natal sering menyebabkan ulkus traumatik pada permukaan depan lidah bayi karena ujung insisal gigi yang tajam, juga sering menyebabkan luka pada puting susu ibu. Gigi natal menyebabkan bayi menjadi kesulitan saat menyusu. Pada beberapa kasus gigi natal, jika terdapat kegoyangan pada gigi maka sebaiknya gigi diambil karena berisiko tertelan dan mengganggu pernafasan.

Pada kasus gigi natal yang menyebabkan ulkus pada gingiva, mukosa oral dan lidah ringan sampai sedang dan tidak terdapat kegoyangan pada gigi maka dilakukan perawatan konservasi dengan menggrinding ujung insisal gigi menggunakan instrumen abrasive secara lembut dan hati-hati. Alternatif perawatan lainnya adalah melakukan tumpatan menggunakan GIC pada ujung insisal gigi [2]. Pada kasus ini, ulkus cukup besar dan jika dilakukan pengurangan insisal edge tetap masih terdapat kontak dan trauma pada gingiva dan lidah bayi, sehingga penyembuhan luka akan tertunda. Dikhawatirkan juga berat bayi akan terus menurun karena kesulitan saat menyusu sehingga harus diambil penyelesaian yang cepat dengan cara melakukan ekstraksi.

Ekstraksi gigi natal sebaiknya dilakukan saat bayi telah berusia diatas 10 hari karena flora bakteri yang terdapat pada saluran pencernaan pada bayi yang baru lahir belum efektif memproduksi vitamin $\mathrm{K}$ selama 10 hari pertama 
kelahiran. Vitamin K mempunyai peranan yang besar dalam pembentukan sintesis protrombin di hati (Semih Sert dkk, 2004).

\section{Kesimpulan}

Perawatan gigi natal harus segera dilakukan sebelum menimbulkan masalah lebih lanjut pada bayi. Pada laporan kasus ini, ekstraksi gigi natal merupakan pilihan alternatif yang lebih baik daripada perawatan konservasi. Pertimbangan ektraksi dilakukan karena :

- Ketidaknyamanan bayi pada saat menyusu sehingga dikhawatirkan bayi akan dehidrasi.

- Agar luka pada gingiva, mukosa labial rahang atas dan permukaan ujung lidah bayi tidak semakin parah.

- Mencegah agar gigi tidak tertelan karena saat dilakukan pemeriksaan klinis gigi mengalami kegoyangan.

- Bayi telah berusia 3 bulan sehingga ekstraksi yang dilakukan tidak dikhawatirkan akan menimbulkan pendarahan karena produksi vitamin $\mathrm{K}$ pada saluran pencernaan bayi sudah efektif.

\section{Referensi}

[1] Anegundi RT, Sudha P, Kaveri H, Sadanand K (2002). Natal and Neonatal Teeth: A report of four cases. J Indian Soc Pedo Prev Dent, 20(3): 86-92.

[2] Baghdadi Z.D (2001) Riga-Fede desease : Report of a case and review. J. CI Fed Dent, 25:209-13.

[3] Cameron AC, Widmer RP (2000). Handbook of Pediatric Dentistry. Ed 4th. Mosby Elsevier, Toronto: 320.

[4] Christiono S (2009). Manajemen Natal Teeth: Laporan Kasus. UNISSULA. 1-4.Al varez MP Leung KC, Robson W (2006). Natal Teeth: A Review. J of the National Med Association, 98(2): 226-8.

[5] Lipsky M, King M, Hunsaker M, Susman J, Bales R (2011). Family Medicine Certification Review. Ed 2nd.Wolters Kluwer, Philadephia: 105 .

[6] Magitot, E. (1878): De leeruption precoce des dents temporaires. Gaz. des Hop., 49:412-427. www.paediatrics.org. diakses pada tanggal 18-4-2010

[7] Semih Sert, Cengiz Özçelik, Jale Tanalp (2004). Natal teeth (a case report). Istambul, Turkey OHDMBSC - Vol. III No. 1 - March, 2004. 